\title{
Os sátiros: marginalização ou representação do humano
}

\author{
Vanessa Ribeiro Brandão \\ Mestranda em Estudos Clássicos pelo Programa de Pós-Graduação em Letras: Estudos \\ Literários (Pós-Lit) - FALE / UFMG
}

\begin{abstract}
RESUMO
Neste ensaio serão abordados os sátiros, seres mitológicos gregos geralmente representados metade homem e metade bode, com um falo ereto. A base para a análise serão os dramas satíricos e histórias mitológicas gregas das quais eles fazem parte, relacionando-os aos costumes, à moralidade grega da época e à condição humana.
\end{abstract}

\section{PALAVRAS-CHAVE}

Sátiros, monstros, drama satírico

Os monstros realmente existem? Eles seguramente devem existir, pois se eles não existissem, como existiríamos nós?

\section{J. J. Cohen ${ }^{1}$}

O monstruoso faz parte de qualquer civilização ou cultura, pois marca o excesso, o horror e as diferenças de diversas índoles, que vão desde as diferenças políticas, raciais, econômicas ou até mesmo sexuais e que se concentram na deformação da criatura. A cultura grega deixou vários exemplares dessa estranha categoria, como as sereias, que tentam seduzir, com suas histórias, o herói Ulisses $;^{2}$ o Ciclope, que devora os companheiros do herói $;^{3}$ as erínias, que latem atrás dos culpados por derramar sangue familiar. ${ }^{4}$ Neste ensaio, analisaremos a monstruosidade dos sátiros tanto pela sua aparência quanto pelo seu

\footnotetext{
${ }^{1}$ COHEN. A cultura dos monstros: sete teses, p. 54 .

${ }^{2}$ HOMERO. Odisseia, canto XII, vv.181-200.

${ }^{3}$ HOMERO. Odisseia, canto IX, vv.166-566.

${ }^{4}$ HESÍODO. Teogonia, vv. 180-185.
} 
comportamento, os quais podem ser charlatães e dissimulados, quando, no drama satírico Ciclope simulam fidelidade a Polifemo, afirmando que salvaram os bens do amo que Ulisses e os gregos haviam tentado roubar, ${ }^{5}$ ou simplesmente divertidos, quando, no prólogo da mesma peça, usam trocadilhos sexuais para descrever sua lealdade a Dioniso. ${ }^{6}$

De acordo com o que é representado nas pinturas do século V a.C., os sátiros eram metade humanos metade animais, geralmente com corpo de homem, com uma barba, patas de bode, pequenos chifres e rabo de cavalo ou qualquer outro caprino, além de exibirem divertidamente - ou de forma aterradora, nas imagens de perseguição sexual - seus falos eretos. São seres brincalhões - ou desrespeitosos - como crianças e têm inclinações patológicas pela busca da "satisfação imediata dos instintos elementares, como o básico elementar da sobrevivência ou o luxuoso e gratificante do sexo". 7 São capazes de fazer qualquer coisa por bebida e sexo, inclusive enganar grandes heróis gregos, como já foi citado o episódio com Ulisses; ou ferir e abusar dos mais indefesos, como acontece no drama satírico Diktyoulkoí ("puxadores de rede de pesca"), ${ }^{8}$ quando encontram Danae e o pequeno Perseu dentro do baú trazido pela maré e Sileno chama a si mesmo de "um protetor ao mesmo tempo benfeitor e defensor / da criança, uma ama assim velha / a qual o colocará na cama com palavras suaves". 9

São justamente as características físicas e comportamentais dos sátiros que os tornam monstruosos. Afinal, segundo Jeffrey Jerome Cohen, em texto intitulado "A cultura dos monstros: sete teses", é a mistura de seres naturais com comportamentos extravagantes que demonstra caráter híbrido e único que o monstro tem, ou seja, uma "recusa a fazer parte da ‘ordem classificatória das coisas' (...): eles são híbridos que perturbam, híbridos cujos corpos externamente incoerentes resistem a tentativas para incluí-los em qualquer estruturação sistemática." ${ }^{, 10}$

Nessa perspectiva, os sátiros são monstruosos e assombrosos justamente porque é difícil classificá-los e identificá-los com o que é comum; eles ficam à parte, na alteridade,

\footnotetext{
${ }^{5}$ EURÍPIDES. O Ciclope, vv.228-53.

${ }^{6}$ EURÍPIDES. O Ciclope, vv.1-17.

7 "satisfacción inmediata de los más elementales instintos, como el básico y elemental de la supervivência y el lujoso y gratificante del sexo". EIRE, Reflexiones sobre la lengua del drama satírico, p.93.

${ }^{8}$ AUN. Diktyoulkoí - um drama satírico de Ésquilo, p. 85.

${ }^{9}$ AUN. Diktyoulkoí - um drama satírico de Ésquilo, p.87, vv.769-771. (grifos nossos)

${ }^{10}$ COHEN. A cultura dos monstros: sete teses, p. 30.
} 
porém não completamente isolados. No limiar, ou melhor, no limite do que é o comum dos homens, eles materializam diferenças do que é culturalmente aceito. Essas diferenças representam o horrendo que faz parte daquela cultura e dos seres humanos que dela participam. $^{11}$

Cohen reafirma isso ao citar René Girard, que explica: “os monstros nunca são criados ex nihilo, mas por meio de um processo de fragmentação e recombinação, no qual se extraem elementos de "várias formas'."12 Da mesma forma, os sátiros são criados a partir de animais já existentes, como o homem, o cavalo e o bode, e com características que podem ser relacionadas a seres da alteridade da pólis grega, apaídeutoi, ${ }^{13}$ como crianças, bêbados como os jovens gregos, ${ }^{14}$ diferenças incômodas, mas que são bem reais.

Percebe-se, assim, que todo monstro é próprio de sua cultura e ele surge com o intuito de revelar algo sobre ela, já que "o monstrum é, etimologicamente, 'aquele que revela', 'aquele que adverte'(...)". ${ }^{15}$ Dessa forma, é possível "ler as culturas a partir dos monstros que elas engendram", ${ }^{16}$ uma vez que "pode-se pensar a categoria do monstruoso a partir de certas metáforas, no campo das relações entre o normal e o anormal, a fim de se rastrear antropologicamente a tensão entre igualdade e diversidade" ${ }^{17}$

Os sátiros, além de inúmeras outras funções (na cerâmica, mitologia, épica), aparecem na cultura helênica como protagonistas e coro de um gênero teatral que se chamou de "drama satírico". O gênero recebe esse nome justamente pelo fato de os sátiros formarem o coro que interage com as personagens. É especificamente um gênero dramático grego contemporâneo à comédia e à tragédia, apreciado nos festivais dionisíacos. Mitológico e burlesco, era

${ }^{11}$ COHEN. A cultura dos monstros: sete teses, p.29.

${ }^{12}$ COHEN. A cultura dos monstros: sete teses, p.39.

${ }^{13}$ Segundo o verbete do dicionário grego-inglês LIDDELL and SCOTT, $\pi \alpha i ́ \delta \varepsilon v \tau o \zeta, ~ d e ~ \pi \alpha 1 \delta \varepsilon v ́ \omega: 1$. Uneducated (não-educado), Eur., Plat.:- c. gen. uninstructed in a thing (não-instruído em algo), Xen. 2. Ignorant (ignorante), boorish (rude), coarse (grosseiro), Eur., Plat; segundo o Miniléxico

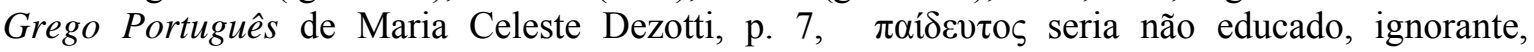
grosseiro. O radical $\pi \alpha \imath \delta-$, similar ao radical de $\pi \alpha i ́ s$, criança.

${ }^{14}$ GRIFFITH. Satyrs, citizens, and self-presentation, p. 176.

${ }^{15}$ COHEN. A cultura dos monstros: sete teses, p.27.

${ }^{16}$ COHEN. Pedagogia dos monstros, p.2.

17 "Se puede pensar la categoría de lo monstruoso desde ciertas metáforas, en el campo de las relaciones entre lo normal y lo anormal, a fin de ratrear antropológicamente la tensión entre Mismidad y Otredad." COLOMBANI. Montruos, crímenes y otros. Construyendo el 'topos' de La degeneración, p. 88. 
apresentado após as tragédias, que, na perspectiva aristotélica, seriam supostamente solenes. ${ }^{18}$ Nos espetáculos das Grandes Dionisíacas, os dramaturgos selecionados apresentavam as tragédias em grupos de três, para, em seguida, encerrarem sua obra com um drama satírico. ${ }^{19}$ Infelizmente, são poucos e fragmentados os textos desse gênero que chegaram até nós.

Algumas peças e fragmentos a que temos acesso exibem os coros de sátiros, liderados pelo corifeu Sileno, pai deles, que apresenta as mesmas características que os filhos, porém é velho e, por isso, desdentado e calvo. Sua calvície é útil, poética e, linguisticamente, uma fonte de trocadilhos bem-humorados com "a careca" do falo ereto, como na observação que Sileno faz sobre o jovem Perseu, no drama satírico esquiliano: "Com alegria ri de mim, ele, o pequeno, / olhando para a brilhante / e de intenso vermelho careca." ${ }^{20}$

Porém, como explicar a baixeza do drama satírico logo após a solenidade trágica? Talvez a representação de tal gênero tivesse a função de oferecer bem-estar após a tensão dos ágones trágicos. ${ }^{21}$ Mark Griffith, por sua vez, afirma que "as atividades do Teatro de Dioniso são vistas como contribuintes centrais para a formação e autorrepresentação dos bons (ou não tão bons) cidadãos atenienses". ${ }^{22}$ Dessa forma, o baixo apresentado imediatamente após o solene evidencia a essência de ambos os gêneros e de ambas as representações.

As tragédias concebiam grandes e nobres homens, enquanto o drama satírico misturava heróis - que se identificavam com homens nobres - e semi-homens, que se comportam de forma irresponsável e sem limites, "outra faceta inconfensável ao ser humano, a faceta anti-heroica mais elementar e natural". ${ }^{23}$ No entanto, esses extremos comportamentais não são opostos, mas complementares, no sentido em que representam o homem ateniense do século V a.C. ${ }^{24}$ e, em nosso entender, o homem do passado e do presente. Os sátiros, que cantavam, dançavam furiosamente, gritavam e bebiam incontinentemente, assemelham-se aos jovens aristocratas nos banquetes, que se entregam à bebida e ao sexo. Os atos irresponsáveis

\footnotetext{
${ }^{18}$ ARISTÓTELES. Poética, 1449a-b.

${ }^{19}$ EIRE. Reflexiones sobre la lengua del drama satírico, p.92.

${ }^{20}$ AUN. Diktyoulkoí - um drama satírico de Ésquilo, p.88.vv.786-788.

${ }^{21}$ EIRE. Reflexiones sobre la lengua del drama satírico, p.92, 94.

22 "Thus the activities in the Theater of Dionysos are seen as contributing centrally to the formation and self-presentation of good (or less-than-good) Athenian citizens." GRIFFITH, Satyrs, citizens, and self-presentation, p.161.

23 "la otra faceta inconfesabledel ser humano, la faceta antiheroica más elemental y natural". EIRE, Reflexiones sobre la lengua del drama satírico, p.93.

${ }^{24}$ GRIFFITH. Satyrs, citizens, and self-presentation, p. 174 .
} 
e infantis denunciam o que é primitivo no civilizado cidadão ateniense, ${ }^{25}$ a animalidade que os homens ocultam, mas mostram pelo vinho e pelo frenesi do carnaval. ${ }^{26}$ Acrescente-se ainda que para os bem comportados cidadãos maduros, os sátiros representavam tudo aquilo que eles poderiam ou que teriam vivido nas suas juventudes, mas que agora suprimem e escondem dentro de si para manter o status de representante da pólis.

E nada melhor que um festival Dionisíaco para libertar-se das amarras sociais e comportar-se de maneira bruta e primitiva, "um componente vital da liberdade trazida pela 'escravidão' para Dioniso". ${ }^{27}$ Uma marca dessa vitalidade seria a exibição coral dos sátiros, marcada por gritos e uma dança peculiar:

A dança esperada para a performance do coro e característica do drama satírico é a síkinnis que une a coreografia da pírrica com seus arremessos, tumultos e saltos e uma boa dose de humor. (...) Ela revela a contiguidade entre homem, besta e deus. ${ }^{28}$

Há vulgaridade e baixeza na síkinnis, que, "acompanhada de saltos e cambalhotas, traduzia a exuberância física dos sátiros". ${ }^{29}$ Ela diferenciava esse coro dos que faziam parte dos demais gêneros dramáticos.

O drama satírico trabalha as banalidades e o ridículo nos mitos também tratando os personagens solenes em situações risíveis: deuses, como em Ichneutai (Rastejadores), Apolo tem suas vacas roubadas, sai à procura delas e se submete à ajuda dos sátiros; como em Ciclope, Ulisses é enganado por Sileno e quase morre devorado por Polifemo. O burlesco é ainda marcado pelos incidentes triviais, jogos de cena indecentes, gracejos escatológicos e gestos e danças vulgares, todos performatizados pelos sátiros.

A mistura de personagens nobres e baixos é responsável também pela hibridez do estilo. Há uma mistura nos modos de falar: o grotesco dos sátiros e a excelência dos heróis; o nobre trágico (ou épico) e a comicidade libidinosa dos sátiros; ${ }^{30}$ as loucuras da juventude nos banquetes mostradas pelos sátiros e o exemplo a ser seguido enfatizado pela atuação dos heróis e nobres, mais uma vez, representam a dualidade do cidadão grego. O ridículo a que é

\footnotetext{
${ }^{25}$ GRIFFITH, Satyrs, citizens, and self-presentation, p. 176.

${ }^{26}$ EIRE. Reflexiones sobre la lengua del drama satírico, p.92.

27 "This is one vital component of the freedom bought by 'slavery' to Dionysos." GRIFFITH, Satyrs, citizens, and self-presentation, p.176.

${ }^{28}$ BARBOSA. Fragmentos de drama satírico: Ichneutas, os sátiros rastreadores de Sófocles, p. 5.

${ }^{29}$ BRANDÃO. Um drama satírico: O ciclope e duas comédias: As rãs; As vespas, p. 34.

${ }^{30}$ EIRE. Reflexiones sobre la lengua del drama satírico, p. 92-93.
} 
submetido o herói é geralmente responsabilidade (ou irresponsabilidade) dos sátiros. Isso remete ao controle das paixões, à maturidade do homem da pólis, que reprime seu lado primitivo pelo bem social e para não se entregar ao ridículo.

Todavia, a dicotomia entre os sátiros e o homem adulto ateniense - dicotomia complementar, reiteramos - não se limita ao comportamento social. Há, para esses monstros, um lugar privilegiado à margem da ágora, a saber, os campos e florestas com seus rios, com fontes, grutas e as ninfas parceiras e habitantes naturais do meio não cultivado pelo homem, mas sem sair do "ambiente mitológico da tragédia". ${ }^{31}$ Desse modo, eles são a representação de uma oposição à pólis não só pelo comportamento, mas também pelo meio, como uma espécie de marginalização. Os textos mais completos a que temos acesso, o Ichneutai e o Ciclope, podem comprovar isso.

O primeiro, Ichneutai, passa-se na gruta Cilene, afastada da pólis, pois era o lugar onde Zeus escondeu seu filho bastardo, Hermes, da esposa Hera. Lá, uma ninfa cuidava do bebê-deus que havia roubado as vacas do seu irmão Apolo. Este, sem desconfiar da travessura do meio-irmão, pede aos sátiros que achem seus animais. $\mathrm{O}$ assunto $^{32}$ e o ambiente ${ }^{33}$ pastoris se afastam do núcleo citadino, evidenciando a alteridade do gênero e do coro.

O segundo, Ciclope, se passa numa ilha habitada por ciclopes, figuras, desde Homero, ${ }^{34}$ distantes do mundo civilizado, homens descomunais que não respeitam as tradições, uma vez que não têm o costume de receber bem um estrangeiro, não conhecem o vinho, nem cultivam suas terras. A atitude dos habitantes já evidencia a distância da pólis. Nesse lugar, os sátiros de Eurípides foram escravizados pelo velho Polifemo homérico, que novamente enfrentará o conhecido Odisseu, símbolo da astúcia que libertará os filhos de Sileno. Odisseu salva-os após furar o olho de Polifemo por meio de um plano meticuloso e astuto. Nessa peça, tudo se passa à porta de uma gruta enorme em uma ilha distante da civilização; evidencia-se o monstruoso dos sátiros e do ciclope que é derrotado por uma figura que é socialmente desejada e até venerada pela pólis ateniense.

Nesse contexto, há outras criaturas que se encontram entre as personagens esperadas num drama satírico: as ninfas. Elas são parceiras dos sátiros e, além de personificarem o meio natural, também são relacionadas a funções tipicamente femininas que não cabem a nenhuma

\footnotetext{
${ }^{31}$ EIRE. Reflexiones sobre la lengua del drama satírico, p. 92.

${ }^{32}$ BARBOSA. Fragmentos de drama satírico: Ichneutas, os sátiros rastreadores de Sófocles, vv.11-7.

${ }^{33}$ BARBOSA. Fragmentos de drama satírico: Ichneutas, os sátiros rastreadores de Sófocles, vv.21-43.

${ }^{34}$ HOMERO. Odisseia, canto IX, vv.166-566.
} 
deusa, como o cuidado do lar e a criação dos filhos. ${ }^{35}$ São elas que cuidam dos bebês-deuses, muitas vezes filhos bastardos de Zeus, como Hermes ${ }^{36}$ e Dioniso. ${ }^{37}$

As ninfas habitam as grutas e montanhas com as quais se confundem. Cilene, por exemplo, é o nome do monte onde cresceu o bebê Hermes e da ninfa que dele cuidou. As fendas, furos e curvas do ambiente natural em que elas vivem são materializados nos traços do corpo feminino da ninfa, ${ }^{38}$ o qual pode representar tanto a sensualidade quanto a maternidade, aludindo à sexualidade humana feminina, assim como o falo dos sátiros remetem ao masculino.

Entendendo melhor os sátiros, é possível perceber nuances e detalhes da cultura grega arcaica. Deve-se levar em conta que, nos festivais dionisíacos, esse tipo de drama vinha contrapor o destino trágico à alegria pueril do sexo e da bebedeira. Enquanto a desmedida trágica dá origem à ira dos deuses, as transgressões dos sátiros, inconfessáveis aos seres humanos, são libertadoras e em favor de Dioniso. Vale salientar que ambos os gêneros evidenciam a separação entre deuses e mortais: o primeiro, pelo poder de um sobre o outro; o segundo, pelo comportamento e atitudes primitivas dos sátiros que remetem às paixões próprias do humano, como a covardia e os vícios. Os sátiros seriam mais atraentes e inteligíveis para um setor conservador-reprovador da pólis, já que traziam consigo a visão do mundo e da marginalidade como caricata, exagerada e transgressora.

\begin{abstract}
In this essay we will word the figure of satyrs, mythological Greek creatures usually represented half man and half goat, with an erect phallus. The basis for the analysis will be the satyr dramas and Greek mythological stories which they appear, linking them with customs, values from Ancient Greece and the human condition.
\end{abstract}

\title{
KEYWORDS
}

Satyrs, monsters, satyr drama

\footnotetext{
${ }^{35}$ LARSON. Greek nymphs: myth, cult, lore, p. 5.

${ }^{36}$ Hino Homérico IV a Hermes; SÓFOCLES. Ichneutas.

${ }^{37}$ Hino Homérico VII a Dioniso.

${ }^{38}$ BARBOSA. Representações do feminino no drama satírico: as ninfas, grutas amenas e sombrias, p. 79.
} 


\section{REFERÊNCIAS}

ARISTÓTELES. Poética. 2. ed. Trad. Ana Maria Valente. Lisboa: Calouste Gulbenkian, 2007.

AUN, A. L. G. Diktyoulkoí - um drama satírico de Ésquilo. Nuntius Antiquus, v. 4, p. 82-91, dez. 2009. Disponível em: <http://www.letras.ufmg.br/nuntius/data1/arquivos/004.07AnaAun82-91.pdf $>$. Acesso em: 20 fev. 2011.

BARBOSA, T. V. R. Fragmentos de drama satírico: Ichneutas, os sátiros rastreadores de Sófocles, 2008a. (relatório de pós-doutorado)

BARBOSA, T. V. R. Representações do feminino no drama satírico: as ninfas, grutas amenas e sombrias. Humanitas, v. 60, p. 75-86, 2008 b.

BRANDÃO, Junito de Souza. O drama satírico. In: EURÍPIDES; ARISTÓFANES. Um drama satírico: O ciclope e duas comédias: As rãs; As vespas. Rio de Janeiro: Espaço e Tempo, 1987. p. 31-35.

COHEN, Jeffrey Jerome. A cultura dos monstros: sete teses. In: SILVA, Tomaz Tadeu. Org. e trad. Pedagogia dos monstros - os prazeres e os perigos da confusão de fronteiras. Belo Horizonte: Autêntica, 2000. p. 1-60.

COLOMBANI, María Cecilia. Montruos, crímenes y otros. Construyendo el topos de la degeneración. Aletria, v. 20, n. 3, p. 85-101, set.-dez. 2010. Disponível em:< http://www.letras.ufmg.br/poslit/08_publicacoes_pgs/Aletria\%2020/n\%203/07-

Cecilia\%20Colombani.pdf $>$. Acesso em: 20 fev. 2011.

DEZOTTI, Maria Celeste Consolin. Miniléxico Grego Português. FCL - UNESP, Araraquara, 2000.

EIRE, A. LÓPEZ, Reflexiones sobre la lengua del drama satírico. Humanitas, v. 52, p. 91$122,2000$.

EURÍPIDES. O cilope. In: EURÍPIDES; ARISTÓFANES. Um drama satírico: O ciclope e duas comédias: As rãs; As vespas. Tradução e comentários de Junito de Souza Brandão. Rio de Janeiro: Espaço e Tempo, 1987. p. 42-68.

HESÍODO. Teogonia: a origem dos Deuses. 6. ed. Tradução, estudo e notas de Jaa Torrano. São Paulo: Iluminuras, 2006.

HOMERO. Odisseia. 3. ed. Trad. Carlos Alberto Nunes. São Paulo: Tecnoprint, 1960.

LARSON, Jennifer Lynn. Greek nymphs: myth, cult, lore. Oxford University Press, 2001.

LIDDELL and SCOTT. Greek Lexicon - Perseus Digital Library. Disponível em: $<$ http://www.perseus.tufts.edu/hopper/resolveform?redirect=true> Acesso em: 20 fev. 20011.

GRIFFITH, Mark. Satyrs, citizens, and self-presentation. In: HARRISON, George W. M. (Ed.). Satyr drama - Tragedy at Play. Swansea: The Classical Press of Wales, 2005. p. 161199.

PERSEUS DIGITAL LIBRARY. Disponível em: < http://www.perseus.tufts.edu>. Acesso em: 20 fev. 2011.

SÓFOCLES. Os rastejadores. In: . Tragédias do Ciclo Troiano - Ajax, Electra, Filoctetes. Trad. E. Dias Palrieira. Lisboa: Sá da Costa Editora, 1973. 
SUTTON, D. The satyr play. A preliminary sketch. In: . Greek satyr play. Meisenheim am Glan: Hain, 1980. p. 134-145. 